\title{
The Effect of Hybrid Computing on Internal Control Systems in Jordanian Commercial Banks
}

\author{
Mohammad Abdel Mohsen Al-Afeef \\ Associate Professor in financial \& banking sciences, Faculty of Business \\ Jerash University, Jerash \\ Jordan \\ Osama Abdul Munim \\ Professor in accounting, Faculty of Business \\ Jerash University Jerash \\ Jordan \\ Jamal Alafeef \\ Associate Professor in accounting, Faculty of Business \\ Jerash University, Jerash \\ Jordan.
}

\begin{abstract}
The current study aimed to identify the effect of hybrid computing on internal control systems in Jordanian commercial banks, where the study community consisted of all Jordanian commercial banks listed on the Amman Stock Exchange, which is (13) commercial banks in 2019, and a comprehensive survey method was used in Choosing a study sample, as the sample included all of the study population. As for the inspection and analysis unit, which is (148), it consisted of individuals working in the higher administrative levels (general managers and executive directors), and the middle administrative levels (managers and heads of the divisions of the Information Technology Department, Risk Management and the Department of Internal Control) in the Jordanian commercial banks. For the purpose of analyzing study data and testing hypotheses, the Statistical Package for Social Sciences (SPSS) program was used in various statistical analyzes, where descriptive statistics and internal consistency factor (Cronbach alpha) were used as well. Multiple linear correlation test using Pearson correlation coefficient was used to test the presence of the Multicollinearity phenomenon, as well as Multiple and Stepwise Linear Regression. The study reached many results, the most important of which was the derivation of a unified concept of hybrid cloud computing, one of the most important dilemmas facing thinkers due to the difference in its characteristics and changing services depending on the model of its publication, as well as its continuous growing role in banks and companies as a development input which makes it applicable widely. Also, there was an emergence of the effect of hybrid computing (technology, finance, strategy requirements, organizational context, and risks) on internal control systems in Jordanian commercial banks. The most important recommendations are embodied in the need for Jordanian commercial banks to highlight the expected benefits from adopting hybrid cloud computing to build more positive attitudes towards that computing without neglecting their ease of use by finding the appropriate and suitable combination of their resources and technological capabilities to raise the efficiency of the control systems applied in them.
\end{abstract}

Keywords: hybrid computing, internal control systems, Jordanian commercial banks, Cloud computing, ASE.

\section{Introduction}

The banking sector is one of the most prominent sectors affected by the information technology revolution in a way that helped in developing the banking business, And because the most prominent feature of banking is the rapid response to keep pace with technological developments that led to major changes in the nature of banking and financial work, it has become dependent on the electronic pillars for its speed and accuracy, and provides information that supports decision-making, enhances competitiveness, and more administrative efficiency of financial and human resources, and improve banking services, which caused major changes in banking.

The main driver of this change may be cloud computing and all its different types that allow banks to use infrastructure and IT 
Applications effectively and economically. Hybrid cloud computing is a set of systems, applications and computer services provided by a private provider outside the work site so that they are on demand to provide a number of Services, in response to requests of hybrid cloud computing, Banks in Jordan have started to receive and adopt hybrid cloud computing, including many telecommunications companies, where users can obtain many solutions and services via the Internet. Therefore, the current study sought to know the effect of hybrid computing on internal control systems in Jordanian commercial banks.

\section{Study Problem}

Although hybrid cloud computing has brought many advantages to banks in many areas, many of these banks are still not aware of their importance to raise the efficiency of their internal control systems. Therefore, the main study problem is summarized as: is there a statistically significant effect at the level of significance $(\alpha \leq 0.05)$ for hybrid computing (technology, finance, strategy requirements, organizational context, and risks) on the internal control systems in Jordanian commercial banks?

\section{Study Hypothesis}

Although hybrid cloud computing has brought many advantages to banks in many areas, many of these banks are still not aware of their importance to raise the efficiency of their internal control systems. Therefore, the main study problem is summarized as: Is there a statistically significant effect at the level of significance $(\alpha \leq 0.05)$ for hybrid computing (technology, finance, strategy requirements, organizational context, and risks) on the internal control systems in Jordanian commercial banks.

\section{The Importance}

In order to understand the factors that can influence the adoption of hybrid cloud computing in banks, we need to understand the background which this technology is based on. This will also enable us to benefit from its positives and prevent its risks (Marston et al. 2011). Here are some of the key technologies behind cloud technology that consist of the following:

- Network computing: It works as a network consisting of a large number of computers that run together to obtain a wide range of computing resources (TechVentive, 2015).

- Virtualization: The software layer that is managed by devices and the operating system is called the virtual layer, and this layer is what cloud technology is based on. This virtualization layer takes user requests, and then allocates qualitative computing resources dynamically, as virtualization technology helps to use servers more efficiently. (Grossman, 2009)

- Multiple Lease: This technology is based on both software engineering and virtual server collaboration, for example: a server-based program that serves more than one tenant in a multi-rental architecture, software and hardware can work simultaneously to meet the demands of many customers. (Marston et al., 2011).

\subsection{Cloud Computing Services:}

Cloud computing provides its services in three forms: (IaaS), (PaaS), (SaaS), and we will provide a brief explanation of these services:

- Infrastructure as a Service (IaaS): A set of IT equipment owned, managed, and maintained by the cloud provider to be used by cloud customers through on-demand payment system. (Gartner, 2009).

- Platform as a Service. (PaaS): This system provides parts of the infrastructure and intermediaries without the need to manage the resources that contain the software. This means allowing cloud clients to create and control their applications through the cloud. These services include databases. Distribution, application development integration, and administrative tools.

- Software as a Service (SaaS): This system allows cloud clients to access applications and their associated data without the complication of purchasing and installing applications at home (Adel, et. Al., 2013).

\subsection{Cloud Models of Cloud Computing}

There are several forms for clouds applied to different banks and companies: We will give a description of them as follows: 
- Private Cloud: This form facilitates the work of a company and a bank that has many consumers and customers, this platform is usually integrated within the company and internal bank firewalls. This cloud is either owned, managed, or operated by the organization itself or via a third-party provider cloud (Wyld, 2010).

- Public Cloud: This form is used when there are a large number of consumers and clients such as the general public, small, medium or large companies, or banks. Where it may be owned, managed by a commercial, academic or governmental organization, it may be located on the website of the Cloud Service Providers

- Community Cloud: This model uses multiple rental sites to share resources with many users of the cloud. It may be owned, maintained, and operated by a single company and bank or many companies and banks or by a third party providing the service as it may be on or off the site.

- Hybrid Cloud: This model is a combination of two or more premium cloud infrastructures (private, public or community) that carry a "unique entity, but linked together by a unified technology that enables cloud data and applications. This model is more suitable for medium-sized companies and large banks that have limited resources (Wyld, 2010).

\subsection{Hybrid Computing Its Concept, Models and the Special Factors for Its Adoption}

Many definitions of hybrid cloud computing were derived as a type of cloud computing deployment architectures. (Berg, 2015) believes that hybrid cloud computing is a mixture of public and private cloud services in light of the use of the architecture of hybrid cloud properties. So that it is not necessary for the recipient to have a private cloud computing to use the hybrid ones.

Or is it the integration between those types and fixed data centers in the workplace within business organizations to establish a homogeneous hosting environment. Where the applications and their individual components are published and developed in the most appropriate sites for hosting environments (third party: the service provider) while ensuring that the requirements of those applications are provided and linked between those environments (Garrison et al., 2015), The hybrid cloud computing architecture model is summarized in its available characteristics as follows: (Hill et al., 2013).

- Enabling network access: In the hybrid cloud computing model, separate cloud computing models are accessed via different networks if they are not integrated.

- Self-service on demand: The different self-service interfaces for different computing models within the use of hybrid cloud computing, generates the need to build a unified self-service interface for beneficiaries.

Pay-per-use: The Hybrid Cloud Computing self-service interface allows the integration of all the models under it, which creates the ability to standardize invoices using technology resources from those models. This interface also takes into account the issuance of a unified form of invoices instead of collecting the invoices resulting from each cloud computing model individually, and thus reduces the complexity.

Resource Labeling: In the hybrid cloud computing model, technology resource sharing is enabled internally between integrated (public, private, and community) cloud computing models.

Rapid flexibility: Flexibility is the ability to allocate technological resources on demand. Flexibility in hybrid cloud computing is the aggregate flexibility of all the elasticity's of its cloud computing models. (Srinivasan et al., 2015.).

\subsection{Core Issues in Adopting Hybrid Cloud Computing Services}

There are several fundamental factors that decision-makers must consider when accepting the use of hybrid cloud computing and its services, and among these factors: (kavis, 2014).

- Technological factors: This category of factors focuses on performance, customizability, security, organization, business continuity, and others in the cloud architecture of computing.

- Financial factors: This category of factors revolves around the calculation of Total Cost of Ownership (TCO) for cloud services within the hybrid cloud computing architecture.

- Strategic requirements: The strategic requirements used in business organizations play a fundamental and decisive role in pushing decision makers to gravitate towards specific cloud solutions and services and not others.

- Organizational context: Acceptance of cloud computing models, including hybrids, is subject to an internal organizational assessment of the capabilities and technology skills that business organizations possess to build solutions and applications based on those models. 
- Risks: Diagnosis of risks is a major factor in decision-makers' acceptance of the hybrid cloud computing architecture and services in the context of their organizations, i.e. they must be subject to an organizational framework of governance) that arbitrate expected risks of Adopting Cloud Computing Technologies and Services (for the beneficiary) (Yigitbasioglu, 2015).

\subsection{Internal Control Systems and Their Relationship to Hybrid Computing}

The researchers agree with (Ali, et al, 2019) that the development in the internal control system came to keep pace with developments, events and major changes that covered all industrial, commercial and technological fields, and the resulting outcome in the size and type of companies and banks, the complexity of their operations and the emergence and spread of so-called multinational companies on large areas, where these companies and banks are managed by professional people without their owners. Which necessitated the departments of these companies and banks the need to find and develop effective control systems capable of ensuring protection for their properties and following their work and ensuring that the process of using their resources takes place efficiently and effectively in a manner that achieves their goals, and protects the administration from legal accountability towards all relevant parties and maintain attention to the affairs of the company and the bank. Based on the foregoing, the extent of the need for an internal control system in the context of hybrid computing applications can be summarized in the following points:

- Separation of ownership from management.

- Organizational structure of the project, the bank and its branch.

- Government agencies need for data and information.

Therefore, researchers believe that the development in information technology and the use of hybrid computing has led to increased interest in using best technology practices in the audit and control process, especially in auditing computerized accounting information systems as the use of information technology based on hybrid computing leads to a reduction in the time spent and thus reducing costs and improving the quality of the process Checking. Because the existence of computer information security risks requires providing the appropriate degree of information security and electronic protection for the accounting information systems in the bank. To ensure that the information technology used in the bank helps to achieve and expand its strategy and achieve its goals and build relationships and processes to guide it to monitor the bank's business in order to achieve its goals by maximizing the results taking into consideration the balance of risks against the expected return from information technology as a result of the use of hybrid computing. From this standpoint, researchers also see that hybrid cloud computing can be seen as a bridge between public cloud computing and its private counterpart that enables banks to move the workloads of their technological work to the technological resources of the cloud service provider within the framework of bank policies, costs, and other requirements and influencing factors, which can be Benefit from them in raising the efficiency of their control systems.

\section{Study Methodology}

This study is descriptive and analytical, as it aims to identify the impact of hybrid computing on internal control systems in Jordanian commercial banks, where a questionnaire was designed to collect study data, and appropriate statistical methods were used to test hypotheses and answer questions that were asked in the study problem.

The study community consisted of all Jordanian commercial banks listed on the Amman Stock Exchange, which numbered until the end of 2019 (13) commercial banks, and a comprehensive survey method was used in Choosing a study sample, as the sample included all of the study population. As for the inspection and analysis unit, it consisted of individuals working in the higher administrative levels (general managers and executive directors), ), And the middle administrative levels (managers and heads of the divisions of the Information Technology Department, Risk Management and the Department of Internal Control) in the Jordanian commercial banks. . The number of distributed questionnaires reached (180) questionnaires, while the number of questionnaires retrieved and subject to statistical analysis reached (148) questionnaires, which is $(82.2 \%)$ of the total distributed questionnaires.

The study relied on the following two sources for data collection:

- Secondary sources: which consists of books, periodicals, university theses and publications related to the subjects of study.

- Primary sources: It is represented in the data collected through the questionnaire that was designed in a way that is commensurate with the objectives and hypotheses of the study and its questions.

The questionnaire was distributed to general and executive managers, directors and heads of departments of information technology departments, risks and internal control in Jordanian commercial banks. A five-point Likert 
scale was used to measure the attitudes of the sample individuals towards agreeing to the questionnaire paragraphs and according to the variables of the study model, as following: (5) means Strongly agree, (4) means Agree, (3) means Neutral, (2) and means Disagree (1) Strongly Disagree. The relative importance of the axes and their clauses has been judged, as follows:

Table 1. Determining the relative importance of the responses of the sample members

\begin{tabular}{llll}
\hline Mean & $\begin{array}{l}\text { less } \\
\text { than } \\
2.33\end{array}$ & $\begin{array}{l}\text { From 2.33 to } \\
\text { less than 3.66 }\end{array}$ & $\begin{array}{l}\text { From 3.66 to less than } \\
5.00\end{array}$ \\
\hline $\begin{array}{l}\text { relative } \\
\text { importance }\end{array}$ & Low & Intermediate & High \\
\hline
\end{tabular}

SPSS was used to analyze the study data. The following statistical tools were used:

Descriptive statistics measures, which included arithmetic averages and standard deviations.

Internal consistency coefficient (Cronbach Alpha) to test the stability of the study tool.

Pearson correlation coefficient for testing the presence of the phenomenon of Multicollinearity.

Multiple and Stepwise Linear Regression analysis to test the study hypotheses.

\subsection{Study Tools Stability Test}

The stability of the tool used to measure the variables involved was tested using the Cronbach Alpha Coefficient test, where the scale result is statistically acceptable if the value of the Cronbach alpha is greater than (0.60) (Sekaran, 2006, $311)$, and the closer the value is to $(100 \%)$ This indicates higher stability degrees for the study tool, and given the data in the following table, the coherence coefficient of Cronbach alpha was measured for the study variables and their dimensions and for the study tool as a whole to know the consistency of the answers; And as follows:

Table 2. The values of the internal consistency coefficient for the study tool paragraphs

\begin{tabular}{|c|c|c|c|}
\hline Number & Dimension & $\begin{array}{l}\text { Paragraphs } \\
\text { numbers }\end{array}$ & $\begin{array}{l}\text { Alpha } \\
\text { value }\end{array}$ \\
\hline 1 & Technology & 6 & 0.874 \\
\hline 2 & Finance & 6 & 0.755 \\
\hline 3 & $\begin{array}{l}\text { strategy } \\
\text { requirements }\end{array}$ & 6 & 0.708 \\
\hline 4 & $\begin{array}{l}\text { organizational } \\
\text { context }\end{array}$ & 6 & 0.700 \\
\hline 5 & Risks & 6 & 0.755 \\
\hline \multicolumn{2}{|c|}{ Hybrid computing } & 30 & 0.890 \\
\hline 6 & $\begin{array}{l}\text { Regulatory } \\
\text { environment }\end{array}$ & 6 & 0.780 \\
\hline 7 & Control activities & 6 & 0.775 \\
\hline 8 & Risk assessment & 6 & 0.745 \\
\hline 9 & $\begin{array}{l}\text { Information and } \\
\text { communication }\end{array}$ & 6 & 0.753 \\
\hline 10 & $\begin{array}{l}\text { Monitoring and } \\
\text { control }\end{array}$ & 6 & 0.822 \\
\hline \multicolumn{2}{|c|}{ Internal control systems } & 30 & 0.925 \\
\hline \multicolumn{2}{|c|}{ All paragraphs } & 60 & 0.947 \\
\hline
\end{tabular}

We note from Table (2) that the values of the internal consistency coefficient of Cronbach alpha for all paragraphs of the study tool was (0.947), and their number is (60) paragraph, as the coefficient of Cronbach alpha was (0.890) for the paragraphs of measurement of hybrid computing, while the coefficient of Cronbach alpha was (0.925) for paragraphs of Measurement of internal control systems, and therefore all values are greater than (0.60).

This is an indication of the consistency between the paragraphs of the study tool leading to the reliability and the ability to rely on it to conduct statistical analysis.

\subsection{Describing the Answers of the Respondents}

Arithmetic averages, standard deviations, and relative importance ranks were relied upon to describe the responses of the sample members on the questionnaire paragraph and their dimensions, and the results were as follows:

First: hybrid computing

It included the following dimensions: technology, finance, strategy requirements, organizational context, and risks. 
Table 3. Arithmetic averages, standard deviations, ranks and the relative importance of hybrid computing

\begin{tabular}{lllll}
\hline Dimension & $\begin{array}{l}\text { Arithmetic } \\
\text { averages }\end{array}$ & $\begin{array}{l}\text { standard } \\
\text { deviations }\end{array}$ & Rank & $\begin{array}{l}\text { relative } \\
\text { importance }\end{array}$ \\
\hline Technology & 3.938 & 0.696 & 4 & High \\
Finance & 4.001 & 0.459 & 2 & High \\
Strategy requirements & 3.965 & 0.455 & 3 & High \\
Organizational context & 4.009 & 0.452 & 1 & High \\
Risks & 3.881 & 0.512 & 5 & High \\
Hybrid computing & 3.959 & 0.390 & & High \\
\hline
\end{tabular}

Table 3. indicates the rise in the relative importance of hybrid computing in Jordanian commercial banks, where the arithmetic mean was (3.959) and a standard deviation of $(0.390)$ where (organizational context) dimension came in the first rank, with an average arithmetic of (4.009), and a standard deviation of ( 0.452$)$, and with high relative importance, while (Risk) dimension came in last position, with an average of (3.881) and a standard deviation of (0.512), and with high relative importance, and all dimensions of hybrid computing have emerged with a high relative importance.

\section{Second: Internal control systems}

It included the following dimensions: the control environment, control activities, risk assessment, information and communications, and monitoring and control.

Table 4. Arithmetic averages, standard deviations, ranks, and the relative importance of internal control systems

\begin{tabular}{|c|c|c|c|c|}
\hline Dimension & $\begin{array}{l}\text { Arithmetic } \\
\text { averages }\end{array}$ & standard deviations & ranks & $\begin{array}{l}\text { relative } \\
\text { importance }\end{array}$ \\
\hline Regulatory environment & 4.016 & 0.551 & 3 & High \\
\hline Control activities & 4.069 & 0.510 & 1 & High \\
\hline Risk assessment & 4.019 & 0.567 & 2 & High \\
\hline $\begin{array}{ll}\text { Information } & \text { and } \\
\text { Communications } & \end{array}$ & 3.962 & 0.561 & 4 & High \\
\hline Monitoring and control & 3.913 & 0.665 & 5 & High \\
\hline Internal control systems & 3.996 & 0.466 & & High \\
\hline
\end{tabular}

Table 4. indicates that the relative importance of internal control systems in Jordanian commercial banks has increased, where the arithmetic average was (3.996), and with a standard deviation of (0.466), (control activities) dimension came in the first rank, with an average of (4.069), and with a deviation Standard of (0.510), and with high relative importance, while (monitoring and adjustment) dimension came in the last rank, with a mean of (3.913), with a standard deviation of (0.665), and with high relative importance, and all dimensions of internal control systems appeared with high relative importance.

\section{Study Hypotheses Test}

The study relied in the hypothesis test on the Multiple and Stepwise Linear Regression analysis to answer the study questions, and before performing the hypotheses test,

It was confirmed that the data is free from the phenomenon of multiple correlation, as this phenomenon indicates that there is a near-perfect linear correlation between two or more variables, that amplifies the value of the determination coefficient R2 and makes it greater than its actual value, Therefore, the linear correlation coefficient and the contrast amplification coefficient were calculated for each variable tested, and the results were as follows:

Table 5. Correlation matrix for independent variables

\begin{tabular}{|c|c|c|c|c|c|}
\hline Dimension & Technology & Finance & $\begin{array}{l}\text { Strategy } \\
\text { requirements }\end{array}$ & $\begin{array}{l}\text { Organizational } \\
\text { context }\end{array}$ & Risks \\
\hline Technology & 1.000 & & & & \\
\hline Finance & $0.457 * *$ & 1.000 & & & \\
\hline Strategy requirements & $0.354 * *$ & $0.578 * *$ & 1.000 & & \\
\hline Organizational context & $0.399 * *$ & $0.529 * *$ & $0.692 * *$ & 1.000 & \\
\hline Risks & $0.525 * *$ & $0.545^{* *}$ & $0.500 * *$ & $0.449 * *$ & 1.000 \\
\hline
\end{tabular}

** Significant at the significance level of 0.01 
Table 5. shows that the highest correlation coefficient value appeared between the two independent variables (strategy requirements) and (organizational context), which amounted to (0.692), while the correlation coefficient value between other independent variables was less than that, and this indicates that there is no phenomenon Multicollinearity between independent study variables, where the values of linear correlation coefficient that exceed (0.80) may be considered an indication of the presence of Multicollinearity (Guajarati, 2004, 359), and therefore it can be said that the study sample is free of the problem Multicollinearity.

Results of the main study hypothesis test H0: There is no statistically significant effect at the significance level $(\alpha \leq 0.05)$ for hybrid computing (technology, finance, strategy requirements, organizational context, and risks) on internal control systems in Jordanian commercial banks.

To test this hypothesis, multiple linear regression analysis was used, and the results were as shown in Table 6.

Table 6. H0 hypothesis test results

\begin{tabular}{|c|c|c|c|c|c|}
\hline \multirow[b]{2}{*}{ Dependent Variable } & \multirow[b]{2}{*}{$\begin{array}{l}\text { Independent } \\
\text { Variable }\end{array}$} & \multicolumn{4}{|c|}{ Table of Coefficients } \\
\hline & & B & Standard error & Calculated T & $\begin{array}{l}\text { Significance } \\
\text { level Sig t }\end{array}$ \\
\hline \multirow{5}{*}{ internal control systems } & Technology & 0.161 & 0.040 & 4.025 & 0.000 \\
\hline & Finance & 0.167 & 0.067 & 2.481 & 0.014 \\
\hline & $\begin{array}{l}\text { Strategy } \\
\text { requirements }\end{array}$ & 0.270 & 0.075 & 3.583 & 0.000 \\
\hline & $\begin{array}{l}\text { Organizational } \\
\text { context }\end{array}$ & 0.082 & 0.073 & 1.126 & 0.262 \\
\hline & Risks & 0.264 & 0.059 & 4.477 & 0.000 \\
\hline \multicolumn{2}{|l|}{ Correlation coefficient $\mathrm{R}$} & \multicolumn{4}{|l|}{0.812} \\
\hline \multicolumn{2}{|l|}{$\mathrm{R}^{2}$ coefficient of determination } & \multicolumn{4}{|l|}{0.659} \\
\hline \multicolumn{2}{|l|}{ Calculated F value } & \multicolumn{4}{|l|}{54.921} \\
\hline \multicolumn{2}{|l|}{ Sig. F* } & \multicolumn{4}{|l|}{0.000} \\
\hline
\end{tabular}

* The effect is statistically significant at $(\alpha \leq 0.05)$

The results of Table 6 . indicate that the correlation coefficient $(\mathrm{R}=0.812)$ indicates the relationship between the independent variables and the dependent variable, and the effect of the independent variables (hybrid computing) on the dependent variable (internal control systems) is a statistically significant effect, where the value of $F$ is (54.921), and at the level of significance $(\mathrm{Sig}=0,000)$ which is less than $(0.05)$, it has been found that the value of the determination coefficient $(\mathrm{R} 2=0.659)$ indicates that $(65.9 \%)$ of the variance in (internal control systems) can be explained by the variance in Dimensions of (hybrid computing) all combined.

As for the table of coefficients, it has been shown that the value of B at the (technology) dimension has reached $(0.161)$ and that the value of $\mathrm{T}$ has $(4.025)$ at the significance level $(\mathrm{Sig}=0.000)$,

Which indicates that the effect of this dimension is significant. Accordingly, it is clear that there is a statistically significant effect at the level of $(\alpha \leq 0.05)$ of the technology on the internal control systems in Jordanian commercial banks.

The value of $\mathrm{B}$ at the (finance) dimension has reached (0.167) and the value of $\mathrm{T}$ at it is (2.481), at a level of significance $(\mathrm{Sig}=0.014)$, which indicates that the effect of this dimension is significant. Therefore, it is clear that there is a statistically significant effect at the level of $(\alpha \leq 0.05)$ of finance on the internal control systems in Jordanian commercial banks.

The value of B at the (strategy requirements) dimension was (0.270) and the value of $\mathrm{T}$ was (3.583), and at the level of significance ( $\mathrm{Sig}=0.000$ ), which indicates that the effect of this dimension is significant. Accordingly, it is clear that there is a statistically significant effect at the level of $(\alpha \leq 0.05)$ of the strategy requirements on the internal control systems in the Jordanian commercial banks.

Whereas, the value of B at the dimension (organizational context) reached (0.082) and that the value of $\mathrm{T}$ was (1.126), and at a level of significance $(\mathrm{Sig}=0.262)$, which indicates that the effect of this dimension is not significant. Accordingly, it is clear that there is no statistically significant effect at the level of $(\alpha \leq 0.05)$ of the organizational context on internal control systems in Jordanian commercial banks. 
The value of B at the (Risk) dimension is (0.264) and the value of $\mathrm{T}$ is (4.477), with a significance level $(\mathrm{Sig}=0.000)$, which indicates that the effect of this dimension is significant. Therefore, it is clear that there is a statistically significant effect at the level of $(\alpha \leq 0.05)$ of the risks on the internal control systems in the Jordanian commercial banks.

Based on the above, we reject the main null hypothesis and accept the alternative hypothesis:

"There is a statistically significant effect at the level of significance $(\alpha \leq 0.05)$ for hybrid computing (technology, finance, strategy requirements, organizational context, and risks) on internal control systems in Jordanian commercial banks"

To determine which dimensions of hybrid computing have more impact on internal control systems, stepwise regression analysis was used, and the results were as shown in Table (7).

Table 7. Results of the stepwise regression analysis of the main hypothesis H0.

\begin{tabular}{|c|c|c|c|c|c|c|}
\hline Mode & $\begin{array}{l}\text { Internal Control } \\
\text { Systems }\end{array}$ & B & $\mathrm{T}$ & $\mathrm{R}^{2}$ & $\mathrm{~F}$ & Sig* \\
\hline First & Risks & 0.614 & 11.044 & 0.455 & 121.976 & 0.000 \\
\hline \multirow[t]{2}{*}{ Second } & Risks & 0.427 & 7.564 & \multirow[t]{2}{*}{0.581} & \multirow[t]{2}{*}{100.666} & \multirow[t]{2}{*}{0.000} \\
\hline & $\begin{array}{l}\text { strategy } \\
\text { requirements }\end{array}$ & 0.420 & 6.610 & & & \\
\hline \multirow[t]{3}{*}{ Third } & Risks & 0.307 & 5.272 & \multirow[t]{3}{*}{0.639} & \multirow[t]{3}{*}{84.975} & \multirow[t]{3}{*}{0.000} \\
\hline & $\begin{array}{l}\text { strategy } \\
\text { requirements }\end{array}$ & 0.384 & 6.445 & & & \\
\hline & Technology & 0.190 & 4.798 & & & \\
\hline \multirow[t]{4}{*}{ Fourth } & Risks & 0.267 & 4.516 & \multirow[t]{4}{*}{0.656} & \multirow[t]{4}{*}{68.207} & \multirow[t]{4}{*}{0.000} \\
\hline & $\begin{array}{l}\text { strategy } \\
\text { requirements }\end{array}$ & 0.315 & 4.929 & & & \\
\hline & Technology & 0.168 & 4.233 & & & \\
\hline & finance & 0.178 & 2.665 & & & \\
\hline
\end{tabular}

* The effect is statistically significant at $(\alpha \leq 0.05)$

The results of the stepwise regression analysis show the order of entry of the variables in the regression model that represents the effect of hybrid computing on internal control systems, where it was found that (Risks) came first, and explained (45.5\%) of the variance in the dependent variable, and when adding (strategy requirements) The interpretation rate has increased to reach $(58.1 \%)$, and the addition of (technology)has led to an increase in the interpretation rate to $63.9 \%$ ), while the interpretation rate has reached (65.6\%) when adding (Finance). We note that the effect of all independent variables was a significant effect at a level of significance less than (0.05), with the exception of the (organizational context) dimension, which showed a non-significant effect.

\section{Conclusion}

Deriving a unified concept of hybrid cloud computing is one of the most important dilemmas facing thinkers because of its different characteristics and changing services depending on its publishing model, as well as its continuous growing role in banks and companies as a development approach, which makes it widely applicable. Hybrid cloud computing has the advantages of its public and private counterparts, which makes it the most appropriate development environment in the twenty-first century that banks can go to in order to develop and improve their information systems in condition that they should have a clear vision of what these banks want to achieve to increase the efficiency of their work at the local and global levels.

The results of the analysis showed an increase in the relative importance of hybrid computing in Jordanian commercial banks, where the arithmetic average was (3.959), and a standard deviation of (0.390), (organizational context) dimension came first in that., and an increase in the relative importance of internal control systems in Jordanian commercial banks, where the arithmetic average was (3.996), and with a standard deviation of (0.466), (control activities) dimension came first in that. The results showed also the effect of hybrid computing (technology, finance, strategy requirements, organizational context, and risks) on internal control systems in Jordanian commercial banks.

Because of the above results, the researchers recommended: 
- The need for Jordanian banks to adopt entrepreneurial thought, which will lead them towards rethinking the formulation of hybrid cloud computing concepts through a mechanism governed by reading the contents of those concepts in accordance with their characteristics and banking services to raise the cloud technologies applied in them.

- Banks wishing to develop their information systems using hybrid cloud computing must rearrange and refine their strategic vision and interests with regard to electronic work in order to eliminate the most important dilemmas they face in adopting and using new and contemporary technologies to raise the efficiency and leadership of banking in them.

- Jordanian commercial banks should highlight the expected benefits of adopting hybrid cloud computing to build more positive attitudes towards that computing without neglecting their ease of use by finding the appropriate and suitable combination.

\section{References}

Adel, A., Reza, S. and Justice O. (2013). Cloud Computing from SMEs Perspective: A Survey-Based Investigation. Journal of Information Technology Management, Xxiv (1), 260-350

Ali O., Al-tahat S., Al-Duleemi, K., Al-Afeef J, and Al-hawamdah, H., (2019), The Impact of the Decisions of the COBIT 5 Committee on the Effectiveness of the Internal Control Systems in the Jordanian Industrial Joint Stock Companies The Journal of Social Sciences Research 5 (11), 1587-1599, URL: https://arpgweb.com/journal/journal/7

Berg, M. (2015). "Managing Microsoft Hybrid Clouds". Kindle Edition. Packt Publishing, Amazon Digital Services LLC

Garrison, G., R. Wakefield \& S. Kim (2015). "The effects of IT capabilities and delivery model on cloud computing success and firm performance for cloud supported processes and operations". International Journal of Information Management, 35 (5), 377-393.

Gartner, A. (2009). Gartner Highlights Five Attributes of Cloud Computing. Is the World's Leading Research and Advisory Company. Gartner, Inc. (NYSE: IT). Retrieved Sep 7th, 2017 from: http://www.gartner.com/newsroom/id/1035013

Grossman, R. L. (2009). `The Case for Cloud Computing, IT Professional, 11(2), 23-48.

Gujarati, D.N. (2004).Basic Econometrics. (4thed.), UNA, New York: McGraw Hill

Hill, R., L. Hirsch, P. Lake \& S. Moshiri (2013). "Guide to Cloud Computing Principles and Practice”. Springer-Verlag Ltd., London.

Kavis, M. (2014). "Architecting the Cloud: Design Decisions for Cloud Computing Service Models (SaaS, PaaS, and IaaS)". First Edition. A John-Wiley \& Sons, Inc., New Jersey.

Marston, S., Li, Z. Bandyopadhyay, S., Zhang, J. and Ghalsasi, A. (2011) 'Cloud Computing the Business Perspective', Decision Support Systems 51(1), 176-189.

Sekaran, U. (2006). Research methods for business: A skill building approach. John Wiley \& Sons.

Srinivasan, A., A. Md\& V. Vijayakumar (2015). "Era of Cloud Computing: A New Insight to Hybrid Cloud". Procedia: Computer Science, Vol.50, 42-51.

Tech Ventive. (2015). Cloud Tutorial: "Technologies Related to Cloud Computing". Retrieved Jul, 1st 2017 from http://thecloudtutorial.com/related. Html

Wyld, D. (2010), The Cloudy Future of Government it: Cloud Computing and the Public Sector around the World', International Journal of Web \& Semantic Technology 1(20), 66-79.

Yigitbasioglu, O. (2015). "External auditors' perceptions of cloud computing adoption in Australia". International Journal of Accounting Information Systems, Vol.18, 46-62. 